\title{
Ciência e não-ciência ou as "Duas Culturas": dominação, quase hostilidade e quase diálogo
}

\author{
Francisco Assis de Queiróz \\ Professor do Departamento de História - FFLCH USP \\ frantota@uol.com.br
}

Recebido em 19/04/2016. Aprovado em 30/04/2016.

Como citar este artigo: Queiróz, Francisco Assis. "Ciência e não-ciência ou as "duas Culturas": dominação, quase hostilidade e quase diálogo”. Intelligere, Revista de História Intelectual, São Paulo, v. 2, n. 1 [2], p. 129-137. 2016. Disponível em $<$ http://revistas.usp.br/revistaintelligere $>$. Acesso em $\mathrm{dd} / \mathrm{mm} /$ aaaa.

Resumo: Neste artigo procura-se apresentar e discutir algumas noções de ciência e cientificidade e suas relações com outras áreas do conhecimento. Essas relações podem ser de dominação, separação ou diálogo. Diversos autores tem procurado construir pontes entre as diversas ciências ou entre estas e o que se chama de não-ciência.

Palavras-chave: ciência, não-ciência, cientificidade, historicidade.

\section{Science and non-science or the "Two Cultures": dominance, almost hostility and almost dialogue}

\begin{abstract}
In this article we seek to present and discuss some notions of science and scientificity and its relations with other knowledge areas. These relationships can be dominance, separation or dialogue. Many authors have sought to build bridges among the various sciences or among them and what is known as non-science.
\end{abstract}

Keywords: science, non-science, scientificity, historicity. 
Talvez Canguilhem pudesse ser incluído na lista daqueles "mestres da suspeita" - suspeita das ilusões da consciência (Marx, Nietzsche e Freud) - que Paul Ricoeur analisou em sua obra $O$ Conflito das Interpretaçoes: Ensaios de Hermenêtica. ${ }^{1}$ Mas ele é homenageado e incluído na lista dos "filósofos na tormenta", título de obra da historiadora e psicanalista Elisabeth Roudinesco, que inclui ainda os nomes de Sartre, Foucault, Althusser, Deleuze e Derrida. Afirma ela que "Todos eles recusaram, à custa do que eu chamaria de uma travessia da tormenta, transformar-se em servidores de uma normalização do homem, a qual, em sua versão mais experimental, não passa de uma ideologia da submissão a serviço da barbárie". ${ }^{2}$

Uma edição especial de 1998 da revista Economy and Society, é dedicada a Georges Canguilhem. Vários dos artigos publicados neste volume foram inicialmente apresentados em uma conferência realizada em Londres, em setembro de 1996, e patrocinado conjuntamente pela revista, a Rede de Pesquisa de História do Presente e da Embaixada da França em Londres. Como afirmam Thomas Osborne e Nikolas Rose na Introdução: "Estamos convencidos de que os desenvolvimentos nas ciências da vida tem implicações fundamentais para a política, a economia e os arranjos sociais das sociedades contemporâneas...". ${ }^{3}$ De fato, como filósofo, médico, historiador das ciências da vida, Canguilhem apresenta contribuições fundamentais para se pensar o desenvolvimento das novas ciências e tecnologias, bem como as novas abordagens sóciohistóricas, em alguma medida delas derivadas, passando pela biotecnologia, as neurociências e neurotecnologias, a bioeconomia e a neuroeconomia, as relações homem-máquina, cérebro-mente e a inteligência artificial, a bioética, etc. São, sem dúvida, áreas de pesquisa extremamente interessantes e desafiadoras para o presente e o futuro.

Mas a perspectiva que procuramos aqui adotar vai no sentido apontado por Nikolas Rose:

Pensar com Canguilhem nos debates atuais sobre o conhecimento, a ciência e a razão é escapar às opções de realismo ou relativismo, racionalismo ou irracionalismo e similares. É reconhecer que a objetividade não é menos objetiva porque ela é construída e histórica, que os cientistas não são menos científicos porque a sua maneira de se envolver com o mundo se dá em momentos e lugares determinados, que a verdade não deixa de ser um valor, porque é uma atitude ética, em vez da qualidade de um mundo além de toda a ética. ${ }^{4}$

Passo a apresentar algumas variações em torno destas considerações. No clássico livro Ideologia e Utopia, de 1929, o sociólogo alemão Karl Mannheim destacava a necessidade de estabelecermos relações com as diversas tentativas de "revisão de nossa concepção de ciência como um todo", ao afirmar:

\footnotetext{
1 Paul Ricoeur, O Conflito das Interpretaçoes: Ensaios de Hermenêtica, ed. Hilton Japiassu (Rio de Janeiro: Imago, 1978). Canguilhem era leitor de Marx, mas não era marxista e, como afirma Elisabeth Roudinesco, era "um leitor voraz da obra freudiana" e captou "como Sartre, na mesma época, a que ponto o homem Freud era um cientista em conformidade com sua própria representação da história das ciências: um cientista dividido entre o erro e a verdade, um cientista capaz de construir um modelo racional que não fosse uma ciência e cujo objeto jamais pudesse ser circunscrito pelo discurso da ciência" (Elisabeth Roudinesco, Filósofos na Tormenta: Canguilhem, Sartre, Foucault, Althusser, Deleuze e Derrida, trad. , ed. André Telles (Rio de Janeiro: Jorge Zahar Ed. , 2007), 55).

2 Roudinesco, ibid., 11.

${ }^{3}$ Thomas Osborne \& Nikolas Rose, "Introdution", Economy and Society, [Vol.27], $2 \& 3$ (1998): 152.

${ }^{4}$ Nikolas Rose, "Life, reason and history: reading Georges Canguilhem today", Economy and Society, [vol.]27, 2\&3 (1998): 161 (154-170); cf. Thomas Osborne, Aspects of Enlightenment: Social Theory, and the Ethics of Truth (London: UCL Press, 1988).
} 
[...] torna-se claro que nossa concepção de ciência é muito mais restrita do que o âmbito dos conhecimentos atuais; e que o conhecimento atingível e comunicável não se restringe, de modo algum, aos limites das ciências atualmente estabelecidas.(...). A diferença entre 'científico' e 'pré-científico' depende, naturalmente, do que pressupomos serem os limites da ciência. ${ }^{5}$

Em 1961, em "Reflexões sobre Cultura e Ciência", conferência proferida na Academia Brasileira de Ciências, afirmava o físico norte-americano Robert Oppenheimer (que foi diretor científico do Projeto Manhattan): "Empregarei essa palavra [ciência] no sentido mais amplo que eu conheço, significando as ciências naturais, as ciências históricas, incluindo assim todos os assuntos a respeito dos quais os homens podem conversar objetivamente". ${ }^{6}$

Em sentido lato, poderíamos pensar a cultura como tudo o que os humanos criaram para sua subsistência material (tecnologia, economia, comércio, ciência como força produtiva), social (família, associações diversas, política) e espiritual ou simbólica (ideologia, valores, crenças, arte). Dizemos também que tudo é história e tudo é cultura: arte, esporte, religião, política, ciência, tecnologia. É outro físico norte-americano que escreve: "Assim como a pintura, a música, a dança e a poesia - que são maneiras de ver, ouvir, mover-se e dizer - a ciência é um aspecto definido da cultura humana". ${ }^{7}$

Pode-se pensar então, a ciência como cultura e a ciência como história? Ou como arte, como Canguilhem se refere à medicina? Arte e ciência não são campos opostos e incompatíveis, como não raro muito se pensa: a ciência como razão, materialista, crítica; a arte como imaginação, sensibilidade, criatividade. A divisão do trabalho se dá também por questão de conveniência. A especialização fez surgir a palavra ciência, assim como "cientista", esta no século XIX. Arte e ciência floresceram juntas: como na Grécia, no Oriente, no Renascimento, no período da Revolução Industrial, no começo do século XX.

Quando nasce a ciência moderna, nasce um novo gênero de literatura, a utopia, com os ingleses Thomas Moore (A Utopia) e Francis Bacon (Nova Atlântida). Entre os que melhor captaram os efeitos da Revolução Industrial na Inglaterra estão os poetas e reformadores românticos que também formaram nossa sensibilidade (William Blake, Coleridge, Wilberforce, John Donne, entre outros). Além disso, "Os cientistas também fizeram parte do movimento romântico"... buscavam a "celebração do espírito humano". 8 A aguda visão do presente pelos literatos, fê-los também projetar luzes sobre o futuro, ainda que este não lhes parecesse tão radiante. Neste sentido, a Inglaterra produziu ainda várias utopias nos séculos seguintes até as mais conhecidas do século XX, como as de Huxley e Orwell.

A ciência e arte já estiveram unidas por uma linguagem comum. Não são formas opostas ou excludentes de ver e compreender o mundo. As dificuldades para se entender o que se passa na ciência moderna tem algo como as dificuldades para se compreender a arte moderna, a literatura, a pintura, a música, enfim, o que vemos e como percebemos.

Deve-se levar em conta, evidentemente, a complexidade de fatores, ou seja, enquanto em física o conceito de "vermelho" diz respeito a um preciso comprimento de onda, em ciências

\footnotetext{
${ }^{5}$ Karl Mannheim, Ideologia e Utopia, trad. , ed. Sérgio Magalhães Santeiro (Rio de Janeiro: Zahar Editores, 2a ed., 1972), 189190.

'Robert Oppenheimer, "Reflexões Sobre Cultura e Ciência", Ciência e Cultura, [Vol. 14], 2 (1962), 87 (Discurso lido a 20 de setembro de 1961, na Academia Brasileira de Ciências).

${ }^{7}$ Joseph Schwartz, O Momento Criativo, trad., ed. Thelma Médici Nóbrega (São Paulo: Editora Best Seller/Círculo do Livro) (1992), 246.

${ }^{8}$ Joseph Schwartz, ibid. , 66.
} 
sociais e na política o mesmo pode estar associado, entre outras coisas, a ideias comunistas ou ainda a realeza, poder real. Por outro lado, acrescenta-se a isso as diferenças na percepção ou na denominação da "mesma cor" que pessoas diversas podem ter, o que não depende apenas de fatores neurofisiológicos, mas também históricos e culturais. Isso mostra, igualmente, o caráter de historicidade da mente humana, ou seja, das diferentes organizações funcionais do cérebro, que variam de um indivíduo para outro, assim como de uma cultura para outra:

A transformação que a mente do homem pode ter conhecido no decorrer dos séculos, e sobre a qual há documentos da literatura e da arte, não significa que, a uma certa altura da história humana, tenha aparecido uma nova anatomia cerebral e que, daquela época em diante, os homens tenham nascido com um cérebro diferente, que os tornava homens do mundo moderno e não mais da Idade Média, do mundo grego e não mais da Idade da Pedra... A transformação concerne, em vez disso, ao modo de funcionar de tal estrutura, ou, na expressão de Luria, como o cérebro trabalha hoje e como trabalhou no passado... Assim como as relações sociais variam na história, essa determinação da atividade cerebral também tem sua evolução histórica. ${ }^{9}$

O que é "lá"? É denominação de lugar, mas também indica determinada frequência sonora $(440 \mathrm{hz})$ e sexta nota da escala musical. Por estes exemplos, cientistas e humanistas ou artistas tratam de objetos ou realidades diferentes? Para Canguilhem,

O objeto em história das ciências nada tem de comum com o objeto da ciência. O objeto científico constituído pelo discurso metódico, é segundo, ainda que não derivado, em relação ao objeto natural, inicial, e que se diria de bom grado, brincando com o sentido, pré-texto. A história das ciências se exerce sobre esses objetos segundos, não naturais, culturais, mas não deriva deles, assim como estes não derivam dos primeiros. ${ }^{10}$

Se tratam de objetos diferentes, como se relacionam ou não as referidas áreas do conhecimento? Nos Manuscritos Econômico-Filosóficos, de 1844, Marx denunciava o estranhamento entre a filosofia e as ciências naturais: "As ciências naturais desenvolveram uma enorme atividade e se apropriaram de um material que aumenta sem cessar. A filosofia, no entanto, permaneceu tão estranha para elas, como elas para a filosofia". E continua: "As ciências naturais subsumirão mais tarde a ciência do homem, assim como a ciência do homem subsumirá as ciências naturais. Haverá, então, uma única ciência". ${ }^{11}$ Mais tarde, dirá que existe uma única ciência e esta é a ciência da história.

Pouco mais de cem anos depois, em 1959, o físico e escritor inglês Sir Charles P. Snow (que trabalhou com cientistas de porte e convivia com historiadores, sociólogos e literatos; ele mesmo se define como um cientista por formação e um escritor por vocação), em The Two Cultures - As Duas Culturas [e a Revolução Científica; com uma segunda edição ampliada de 1963]-, também denunciava a hostilidade entre o que ele chamou de as "duas culturas", ou seja, cientistas e humanistas, cada um dos quais mais apegados ao que julgavam ser as prerrogativas exclusivas de seus campos de conhecimento. Também ele sugere a emergência de algo como uma "terceira

\footnotetext{
${ }^{9}$ Luciano Mecacci, Conhecendo o Cérebro, trad. , ed. Eduardo Brandão (São Paulo: Nobel; Instituto Italiano di Cultura di São Paulo; Instituto Cultural Ítalo-Brasileiro, 1987), 140.

${ }^{10}$ Georges Canguilhem, Estudos de História e de Filosofia das Ciências Concernentes aos Vivos e à Vida, trad. , ed. Abner Chiquieri (Rio de Janeiro: Forense Universitária, 2012), 10.

${ }^{11}$ MARX, Karl, Manuscritos Econômico-Filosóficos, in Os Pensadores, (São Paulo: Abril Cultural, 2a ed, 1978), 13-14.
} 
cultura”, resultado do diálogo entre literatos, historiadores, físicos, médicos, enfim, intelectuais e cientistas em geral. ${ }^{12}$

Como afirma Lepenies,

O conflito entre as duas culturas é anterior ao século XIX. Entretanto, somente quando as consequências culturais e sociais da Revolução Industrial se tornaram aparentes, os contornos ainda indefinidos da civilização tecnológico-científica começaram a se delinear no horizonte e a educação pública começou a atingir parcelas cada vez maiores da população, é que esse conflito passou a ser um tema central do debate político cotidiano. ${ }^{13}$

Mas vale se perguntar até que ponto essa dicotomia se modificou efetivamente ou não. Tenho a impressão de que as constatações de Marx e Snow estão mais presentes do que nunca na universidade em geral, a despeito das palavras de Roland Barthes (1915-1980) em sua aula inaugural da cadeira de Semiologia Literária do Colégio de França, em 7 de janeiro de 1977, quando ele afirmava: "É de bom-tom, hoje, contestar a oposição das ciências às letras, na medida que relações cada vez mais numerosas, quer de modelo, quer de método, ligam essas duas regiões e apagam frequentemente sua fronteira; e é possível que essa oposição apareça um dia como um mito histórico". ${ }^{14}$

Se pensarmos nas nossas universidades, não obstante esforços de muitas pessoas e grupos, essa visão de Barthes talvez seja bastante otimista. Mas não se pode considerar que, em termos ampliados, a literatura inclua os escritos de Euclides, Copérnico, Galileu, Newton, Darwin, assim como a ciência inclua as línguas, a literatura, as humanidades? O know how (saber fazer) da técnica deve se ligar ao know why (saber porquê; compreender) da ciência.

Por onde se daria, então, a superação dessa dicotomia? Seria a emergência da "terceira cultura" de Snow, resultado do diálogo entre literatos, historiadores, físicos, filósofos, biólogos, enfim, intelectuais e cientistas em geral ${ }^{15}$ Barthes, puxando a sardinha para sua brasa, afirma: "Se, por não sei que excesso de socialismo ou de barbárie, todas as nossas disciplinas devessem ser expulsas do ensino, exceto numa, é a disciplina literária que devia ser salva, pois todas as ciências estão presentes no monumento literário". ${ }^{16}$ Isso parece justificar, em alguma medida, a afirmação de Marx de que aprendeu mais com Balzac do que com todos os historiadores e economistas profissionais. No entanto, ele era filósofo, historiador, economista, sociólogo e escritor ao mesmo tempo. Ora, isso deve nos fazer pensar nas fronteiras e limites de nossas disciplinas dentro das chamadas ciências humanas, ousando dizer, inclusive, para além delas.

A despeito de que também desde 1848, na sua obra Futuro da Ciência, Renan dava lugar às ciências históricas e Fustel de Coulanges afirmava que a história é uma ciência e cujo método é o mesmo das outras ciências de observação, muitos historiadores hoje, como afirma Leônidas Hegenberg, procuram situar-se "entre as ciências e as humanidades, mais propensos a inclinar-se em favor destas, muito conscientes da dicotomia entre ciência natural e estudos humanísticos". ${ }^{17}$ Certamente não é comum, em todos os seus elementos, a concepção que diversos autores têm de ciência. Tanto Hegenberg quanto Popper alertam para os mal-entendidos e incompreensões sobre

\footnotetext{
${ }^{12}$ Charles P. Snow. The Two Cultures (Cambridge, UK: Cambridge University Press, 2002).

${ }^{13}$ Wolf Lepenies. As Três Culturas, trad. , ed. Maria Clara Cescato (São Paulo: Editora da Universidade de São Paulo, 1996), 165.

${ }^{14}$ Roland Barthes. Aula - Aula inaugural da cadeira de Semiologia Literária do Colégio de França-pronunciada dia 7 de janeiro de 1977 , trad. , ed. Leyla Perrone-Moisés (São Paulo: Cultrix, 1989), 20.

${ }^{15}$ Charles P. Snow, ibid. , 2002.

${ }^{16}$ Roland Barthes, ibid. , 18.

${ }^{17}$ Leônidas Hegenberg. Método Científico e História (Assis (SP): ITA-FFCL 1963).
} 
a natureza das ciências naturais e seu método quando, por exemplo, cientistas sociais a elas se referem, seja para ressaltar a incomensurabilidade de suas abordagens, seja para defender suas semelhanças.

Associa-se geralmente as ciências naturais à observação, objetividade, quantificação, causalidade e estabelecimento de leis gerais sendo, portanto, chamadas de nomotéticas pela classificação de Windelband, de 1915 (nomos = lei; tithemi = assentar). Por outro lado, são chamadas ideográficas $($ idios $=$ particular; grafe $=$ descrição) as ciências que procuram compreender aqueles fatos que não podem ser objetos de experimentação, que são particulares e irreprodutíveis, como os fatos históricos. Popper chamou de "naturalismo equivocado" a abordagem metodológica "que frisa que está na hora das ciências sociais aprenderem das ciências naturais o que é método científico". Para ele tal pretensão está baseada na crença no "mito do caráter indutivo do método das ciências naturais, e do caráter de objetividade das ciências naturais". ${ }^{18}$ Daí sua crítica e tentativa de refutação do historicismo, que busca estabelecer leis gerais para a história. ${ }^{19}$

Jerzy Topolsky faz uma distinção entre o que ele chama de naturalistas e anti-naturalistas. Os primeiros - incluindo os marxistas - defendem a unicidade da ciência, ressaltando a semelhança fundamental da matéria de investigação nas ciências naturais e sociais; os segundos, ao contrário, ressaltam que há uma diferença essencial na estrutura dos métodos de investigação entre as ciências naturais e sociais. ${ }^{20}$

A noção de lei científica se impõe no século XVII, com Descartes, Boyle, Newton, entre outros, quando a física se torna uma ciência autônoma em relação à filosofia, prosseguindo com a química no século XVIII, a biologia, a psicologia, geologia, geografia, economia, história, sociologia, etc., no século XIX. As ciências sociais, buscando constituírem-se como disciplinas científicas, positivas, pretendiam neutralizar a subjetividade do observador e eliminar qualquer juízo de valor da sua atividade.

A síntese newtoniana passa a ser a inspiração para a filosofia e demais áreas do conhecimento, incluindo a história. Conforme João Paulo Monteiro,

A filosofia de Hume se inspira explicitamente no modelo newtoniano. Ao pretender constituir-se como ciência da natureza humana, destinada a servir de fundamento geral às ciências humanas particulares (moral, estética, política), essa filosofia declara abertamente sua intenção de seguir o caminho e o método da filosofia natural, sobretudo o de seu exemplo mais ilustre, a ciência de Newton. ${ }^{21}$

E comentadores de Hume chegam a afirmar que sua ambição era tornar-se "o Newton das ciências do homem". Analogias com a física de Newton estão presentes na Investigação sobre a Moral, na teoria do conhecimento, na teoria das paixões, assim como referências a Newton na sua História da Inglaterra... A "física newtoniana... era, como vimos, a inspiração e o modelo da própria filosofia de Hume". 22

${ }^{18}$ Karl Popper, Lógica das Ciências Sociais (Rio de Janeiro: Tempo Brasileiro: UnB, 1978).

${ }^{19}$ Ao contrário do historicismo, para o que na tradição alemã se chama historismo, as instituições e a cultura em geral estão sempre mudando, devendo ser estudadas como fatos singulares e particulares da história.

${ }^{20}$ Jerzy Topolsky, Metodología de la Historia (Madrid: Cátedra, 1985), 509. Na perspectiva daquela primeira corrente, ver também: Edward H. Carr, Que é História?, trad. , ed. Lúcia Maurício de Alverga ( Rio de Janeiro: Paz e Terra, 3ª ed., 1982).

${ }^{21}$ João Paulo Monteiro, "Hume e a Gravidade Newtoniana”, Ciência e Filosofia, 1 (1979): 125 (125-140).

${ }^{22}$ João Paulo Monteiro, ibid. , 139. 
É o mesmo caso, em se tratando da história, como destaca Sara Albieri: "No século XVIII, a história, como a filosofia, tem inspiração newtoniana. (...). Quanto a Hume, expressava claramente sua intenção de obter, para a ciência do homem de modo geral, o mesmo estatuto de cientificidade que Newton havia conquistado para a física". ${ }^{23}$ E continua:

Já que todo conhecimento deve fundar-se na experiência, a história constitui para a ciência do homem, ao lado da vida cotidiana, a grande fonte de 'observação' da natureza humana. A história desempenha, portanto, um papel fundamental na filosofia de Hume, na medida em que representa a condição de possibilidade do emprego do método experimental aplicado ao conhecimento da natureza física, também no campo da filosofia moral. ${ }^{24}$

Outro expoente da filosofia moderna, Immanuel Kant (1724-1804),

[...] que estudara profundamente o tratado de Newton [Princípios Matemáticos de Filosofia Natural, de 1687] foi quem deu resposta a estas questões [sobre o conhecimento das leis fundamentais da natureza]. (...). Em 1756 Kant publicou um ensaio onde pretendia estender a teoria de Newton á explicação da origem da natureza. Era a sua 'História da Natureza e Teoria do Céu', onde propunha uma hipótese nebular, baseada na gravitação universal, como origem do Universo. Tudo de acordo com as leis mecânicas newtonianas. ${ }^{25}$

O mecanicismo e certa racionalidade daí decorrentes acabaram criando, como diz Langevin, uma "nova mística", como a expressa na famosa afirmação de Laplace: "Dêem-me as leis de ação entre os átomos e eu lhes direi o futuro do mundo". ${ }^{26}$ Essa "nova mística" (o mecanicismo) passou a intervir em todos os domínios do conhecimento: astronomia, a fisiologia, a filosofia, a ética, a física, economia, biologia, etc. "Com exceção da teologia, nenhum domínio do saber, em princípio, podia se subtrair aos princípios da filosofia mecânica. Por isso, procedendo nesta direção, Thomas Hobbes colocaria também a política sob o signo da filosofia mecânica". ${ }^{27}$ Da mesma forma, para Comte, o estudo das sociedade seria feito à semelhança do estudo da natureza, através da física social, em que as sociedades são regidas por leis; logo, também o passado e, portanto, a história.

Assim, a partir da Idade Moderna todas as ciências passaram a buscar seu Galileu ou seu Newton, num crescente esforço de formalização, incluindo o comportamento humano. Além de Hume e Kant e Hobbes são, de alguma newtonianos, Voltaire, Locke, Smith, entre tantos outros filósofos, cientistas e aspirantes. Como disse certa ocasião uma aluna da psicologia que assistia ao meu curso: "nós, da psicologia, invejamos Newton".

Mas ainda que a ciência tradicional, como a mecânica clássica, já tenha sido mais determinista, mais ligada à noção de causalidade, de maneira necessária e rígida, as novas experiências e fenômenos físicos estudados no final do século XIX até o surgimento da teoria da

${ }^{23}$ Sara Albieri. "David Hume: Filósofo e Historiador", Mediações - Revista de Ciências Sociais, [Vol.] 9, 2 (2004):, 23 (19-36).

${ }^{24}$ Sara Albieri, ibid., 26.

${ }^{25}$ Milton Vargas, "A Influência dos 'Principia' de Newton na Filosofia de Kant", in Milton Vargas, Para uma Filosofia da Tecnologia (São Paulo, Alfa-Omega, 1994), 123.

${ }^{26}$ Paul Langevin, "O Valor Educativo da História das Ciências", in GAMA, Ruy, Ciência e Técnica: Antologia de Textos Históricos (São Paulo: T. A. Queiroz, 1993),13.

${ }^{27}$ Paolo Rossi, O Nascimento da Ciência Moderna na Europa, trad. , ed Antonio Angonese (Bauru, SP: EDUSC, 2001$), 248$. 
relatividade e, principalmente, da mecânica quântica no século XX, provocaram uma transformação radical também em termos conceituais. ${ }^{28}$

Daí as noções correntes, hoje, de previsão provável ou probabilidade e indeterminismo. Mas, até que ponto existe determinação ou indeterminação objetiva na natureza e na história? Em que medida deve ser o objetivo das ciências encontrar leis gerais? Ou, em outro sentido, estas leis não têm também um caráter de localidade? Esse caráter relativo de tempo e espaço, bem como a indeterminação e as questões referentes à interferência do sujeito no ato de medição na mecânica quântica mudaram consideravelmente a perspectiva da ciência nas primeiras décadas do século XX.

Nesse período a física descobriu, na complexidade dos fenômenos elementares, a presença da acausalidade na natureza. ${ }^{29}$ Contudo, ela não é mais ou menos científica quando trabalha com probabilidades e explicações não determinísticas. Ademais, conforme Prigogine (Nobel de Química de 1977) e Stengers, sistemas físicos abertos são produtos de sua história, na medida em que apresentam um caráter de irreversibilidade, de evolução. ${ }^{30}$ Sua teoria das "estruturas dissipativas", bem como outras teorias recentes vindas da física ("ordem implicada" de David Bohm) e da biologia (teoria da evolução de Jantsch), etc., todas "introduzem na matéria os conceitos de historicidade e de processo, de liberdade, de auto-determinação e até de consciência que antes o homem e a mulher tinham reservado para si". ${ }^{31}$

Assim, as oposições quantitativo-qualitativo, objetivo-subjetivo, determinísticoindeterminístico, a experimentação e a verificabilidade ou sua ausência, a repetibilidade ou não, deixam de ser critérios absolutos para se definir o que é ciência ou não ciência. Hegenberg lembra os casos da topologia em matemática e a teoria da evolução, por exemplo, "em que se trata de mutações qualitativas, estudadas qualitativamente, sem que haja apelo a mensurações de qualquer tipo".32 Afirma ainda que "os exemplos [da astronomia, geologia, embriologia] atestam que a ausência de experimentação não é, como se poderia imaginar, empecilho insuperável para o avanço de uma ciência". ${ }^{33}$ Por outro lado, "a experimentação é muito mais viável nas ciências sociais do que normalmente se supõe"34

Dos sistemas físicos à química, geologia, astronomia, etc., pode-se constatar a existência de enunciados singulares decorrentes de sua evolução temporal, histórica, assim como a história

\footnotetext{
${ }^{28} \mathrm{O}$ conhecimento maior do chamado estado sólido, da estrutura íntima da matéria tem apresentado problemas cruciais do ponto de vista filosófico, do conhecimento, da realidade, enfim, dando ensejo a acalorados debates, entre os quais está o famoso debate Einstein-Bohr entre 1925-1935 sobre a relação entre a teoria quântica e a realidade. Ela se constitui, assim, numa contribuição contemporânea fundamental para a história e a cultura em geral. Como exemplo disso e de lançamento de ponte entre as "duas culturas", citamos o livro O Direito Quântico: Ensaio sobre o Fundamento da Ordem Jurídica, do renomado jurista Goffredo Telles Júnior, publicado em 1971. Duas resenhas da obra foram publicadas na revista Ciência e Cultura, da Sociedade Brasileira para o Progresso da Ciência (SBPC). A primeira em janeiro de 1972 , escrita pelo consagrado biólogo e jornalista José Reis e a segunda, em 1974, escrita por Henrique Fleming, então diretor do Instituto de Física da USP. Telles Jr. fala da evolução da vida e, em grande parte do livro, expõe as ideias principais da física moderna e contemporânea estudando, nas palavras de Fleming, as consequências da revolução conceitual introduzida pela Física Quântica sobre os Fundamentos do Direito.

29 Sobre o ambiente sócio-cultural e intelectual e as controvérsias entre os cientistas quanto às questões do determinismo/causalidade e indeterminsimso/acausalidade e a posterior consolidação da acausalidade na interpretação e desenvolvimento da nova mecânica quântica, ver Paul Forman, A Cultura en Weimar, Causalidad y Teoría Cuántica, 19181927: Adaptación de los Físicos y Matemáticos Alemanes a un Ambiente Intelectual Hostil. Introducción, Apéndice y Traducción de José Manuel Sánchez Ron (Madrid: Alianza Editorial, 1984). (Uma tradução portuguesa foi publicada em Cadernos de História e Filosofia da Ciência (Unicamp, Suplemento 2) (1983)).

${ }^{30}$ Ilya Prigogine e Isabelle Stengers, A Nova Aliança: Metamorfose da Ciência, trad. , ed. Miguel Faria e Maria Joaquina Machado Trincheira (Brasília: Ed. da UnB, 1991).

${ }^{31}$ Boaventura de Sousa Santos, Um Discurso Sobre as Ciências (Porto: Edições Afrontamento, 1988), 38.

${ }^{32}$ Leônidas Hegenberg, ibid., 9.

${ }^{33}$ Hegenberg, ibid., 56-57.

${ }^{34}$ Hegenberg, ibid., 57.
} 
também faz apelo a enunciados universais, "o que mostra que nem as ciências naturais são puramente nomotéticas, nem a história é ideográfica”35

Essas concepções e as novas mudanças no campo das chamadas ciências naturais são logo captadas inclusive por historiadores que não eram historiadores das ciências, como o grande medievalista Marc Bloch que escreve, quando prisioneiro dos nazista em 1944, um pequeno grande livro, no qual afirma:

A teoria cinética dos gases, a mecânica einsteniana, a teoria dos quanta alteraram profundamente a noção que ainda ontem qualquer um formava sobre a ciência. Não a diminuíram. Mas a flexibilizaram. Com certeza, substituíram, em muitos pontos, o infinitamente provável, o rigorosamente mensurável pela noção da eterna relatividade da medida. (...). Estamos portanto agora bem melhor preparados para admitir que, mesmo sem se mostrar capaz de demonstrações euclidianas ou de imutáveis leis de repetição, um conhecimento possa contudo pretender ao nome de científico. ${ }^{36}$

Ele está falando das teorias quântica e relativística, assim como o historiador, diplomata e teórico das relações internacionais Edward Carr, em conferências na Universidade de Cambridge em 1961:

[...] alguns físicos, de uns anos para cá, vêm falando de sua ciência em termos que parecem sugerir as mais surpreendentes analogias entre o universo físico e o mundo do historiador. Em primeiro lugar, diz-se que seus resultados envolvem um princípio de incerteza ou de indeterminação. (...). Em segundo lugar, dizem-nos que na física moderna as distâncias no espaço e os lapsos de tempo têm medidas que dependem do movimento do 'observador'. Na física moderna todas as medidas estão sujeitas a variações inerentes devido à impossibilidade de estabelecer uma relação constante entre o 'observador' e o objeto sob observação; tanto o 'observador' quanto a coisa observada - tanto o sujeito como o objeto - entram no resultado final da observação. ${ }^{37}$

É assim que diversos autores têm apontado para a emergência de novos paradigmas ou de novas abordagens com relação à ciência, ao conhecimento e à cultura. Nas palavras de Prigogine e Stengers, "Chegou o tempo de novas alianças, desde sempre firmadas, durante muito tempo ignoradas, entre a história dos homens, de suas sociedades, de seus saberes, e a aventura exploradora da natureza". ${ }^{38}$ É também essa abertura que Claude Debru destaca tratando de Canguilhem:

Canguilhem não estava preso a uma polêmica contra a filosofia dos filósofos, não mais do que a uma defesa da filosofia da ciência. Ele veio de outro lugar. Isto lhe permitiu ver outras coisas, captar com o mesmo olhar realidades distintas e opostas, o normal e o patológico, a ciência e a não-ciência, sempre disposto a atribuir ao negativo uma existência, uma positividade própria, um

\footnotetext{
${ }^{35}$ Hegenberg, ibid, 86.

${ }^{36}$ Marc Bloch. Apologia da História, ou, O Ofício de Historiador, trad. , ed. André Telles (Rio de Janeiro: Jorge Zahar Ed., 2001), 49.

${ }^{37}$ Edward H. Carr. Que é História?, trad. , ed. Lúcia Maurício de Alverga (Rio de Janeiro: Paz e Terra, 3a ed., 1982 ), 106.

${ }^{38}$ Ilya Prigogine e Isabelle Stengers, A Nova Aliança: Metamorfose da Ciência, trad. , ed. Miguel Faria e Maria Joaquina Machado Trincheira (Brasília: Ed. da UnB, 1991), 226.
} 
interesse merecido. (...). Esta capacidade de representar os opostos e de articulá-los dá, a seus pensamentos, tensão, força, mas também uma amplitude e abertura incomuns. ${ }^{39}$

\section{Referências bibliográficas}

Georges Canguilhem, The decline of the idea of progress, Economy and Society, [vol.] 27, 2\&3 (1998): 313-329.

Georges Canguilhem, O Normal e o Patológico, trad., ed. Maria Thereza Redig de Carvalho Barrocas (Rio de Janeiro: Forense Universitária, 2014).

${ }^{39}$ Claude Debru, Georges Canguilhem, Science et Non-Science (Éditions Rue d'Ulm/Presses de l'École Normale Supérieure, 2004), 82-83. 